\title{
USING REAL-LIFE DATA WHEN TEACHING STATISTICS: STUDENT PERCEPTIONS OF THIS STRATEGY IN AN INTRODUCTORY STATISTICS COURSE
}

\author{
DAVID L. NEUMANN \\ Griffith University \\ d.neumann@griffith.edu.au \\ MICHELLE HOOD \\ Griffith University \\ m.hood@griffith.edu.au \\ MICHELLE M. NEUMANN \\ Griffith University \\ michelle.neumann@griffithuni.edu.au
}

\begin{abstract}
Many teachers of statistics recommend using real-life data during class lessons. However, there has been little systematic study of what effect this teaching method has on student engagement and learning. The present study examined this question in a first-year university statistics course. Students $(n=38)$ were interviewed and their reflections on the use of real-life data during the classes were coded into themes. Resulting themes were (a) relevant perspective in learning, $(b)$ interest, (c) learn/remember material, (d) motivation, (e) involvement/engagement, and (f) understanding of statistics. The results indicate both cognitive and affective/motivational factors are associated with using real-life data to teach statistics. The results also suggest the features in data sets statistics teachers should look for when designing their lessons.
\end{abstract}

Keywords: Statistics education research; Engagement

\section{INTRODUCTION}

In the past, university statistics courses have been criticised for being overly rigid and abstract and for using teaching methods that remove much of the enjoyment from learning (Hogg, 1991; Willett \& Singer, 1992). Such factors appear particularly important for students studying social science degrees because many of them have negative attitudes or anxiety towards statistics (Onwuegbuzie \& Wilson, 2003; Tremblay, Gardner, \& Heipel, 2000). For such reasons, several approaches to improve statistics teaching have been developed. For example, Moore (1997) suggested more integration among course content, pedagogy, and technology. Specific teaching strategies to achieve this can include computer-based activities (e.g., Morris, Joiner, \& Scanlon, 2002) and interactive multimedia (e.g., González \& Birch, 2000). The importance of engendering positive affect and perseverance in students has also been noted (Budé, Van de Wiel, Imbos, Candel, Broers, \& Berger, 2007). In addition to research on specific strategies, broader changes to curriculum and teaching approaches have been proposed. These include emphasising statistical thinking, using less theory and more data, making data analysis central, building intuition, fostering active learning, and using context to develop statistical inference (Cobb, 1992; Makar \& Ben-Zvi, 2011; Scheaffer, 2001).

The application of real data in the teaching of statistics is an approach that has been increasingly recommended in the field of statistics education. The Curriculum Action Project of the Mathematics Association of America in the 1990s included in its guidelines the need for more data in teaching

Statistics Education Research Journal, 12(2), 59-70, http://iase-web.org/Publications.php?p=SERJ

C International Association for Statistical Education (IASE/ISI), November, 2013 
(Cobb, 1992). Later, the Quantitative Literacy Project materials were developed. These materials targeted the secondary level, unlike the Curriculum Action Project of the Mathematics Association of America. In describing these materials, Scheaffer (2001) noted that real-life data should be used when teaching statistics, particularly data that is of interest and relevance to the students. In 2005, the Guidelines for the Assessment and Instruction in Statistics Education (GAISE) by the American Statistical Association included the recommendation to use real data in achieving the desired learning goals (Franklin \& Garfield, 2006). Similarly, national curriculum guidelines for the teaching of statistics in Australia, the United Kingdom, South Africa, and New Zealand all emphasise the need to use real data in teaching (Connor \& Davies, 2002). The notion of developing a Statistical Reasoning Learning Environment (Garfield \& Ben-Zvi, 2009) highlights the role of real and motivating data in developing the statistical reasoning skills of students. Current handbooks that are written to provide guidance and strategies for statistics teachers also include the recommendation to use real data in teaching (Dunn, Smith, \& Beins, 2007; Garfield \& Ben-Zvi, 2008; Hulsizer \& Woolf, 2009). In general, many other statistics educators argue for the use of real data in teaching statistics (see also, Bradstreet, 1996; Diamond \& Sztendur, 2002; Holmes, 2002; Neumann, Neumann, \& Hood, 2010; Rumsey, 2002; Singer \& Willett, 1990).

From a theoretical perspective, the application of real data in teaching statistics aligns several theories of learning. Within a constructivist theory of learning, students will construct knowledge based on their experiences using real data sets (Cobb, 1992; Garfield \& Ben-Zvi, 2009). New knowledge is integrated with previous knowledge regarding the interpretation of the data using relevant statistics. The data sets should be used so that students have the opportunity to reflect upon their work with the data, with the teacher providing just enough guidance to assist the student to build their own understanding. Real data sets also provide a context to a statistical problem. Context may be based on data or it may be based on the physical and social learning environment (Pfannkuch, 2011). Students may develop their statistical reasoning through an interaction between their contextual knowledge about the data set and their emerging statistical knowledge (Dierdorp, Bakker, Eijkelhof, \& van Maanen, 2011; Pfannkuch, 2011).

Data sets can be used by students to practice calculations, gain experience in the interpretation of results, and develop their statistical reasoning about a problem (Garfield \& Ben-Zvi, 2009). Teachers may also use data sets to illustrate different research approaches, methods of data analysis, and applications of statistical theory to solve real-life problems. For example, Morgan (2001) provided an instructive account of how data collected from obituaries published in a local paper was used to teach undergraduates in psychology and secondary education. The resulting data set was used to teach the principles of outlier identification and interpretation, the principles of dealing with messy data, the principles of interpreting correlations, and the principles of presenting data in a report.

Real data can come in different types (American Statistical Association, 2005). A broad distinction may be made between real-life data (e.g., archival data, data collected in research projects, classroom-generated data) and artificial data (e.g., hypothetical or simulated data). The use of real-life data is suggested to have significant advantages. Made up data reinforces the perception that statistics is artificial, dreary, and uninteresting (Singer \& Willett, 1990). In contrast, real-life data may be a motivating tool that makes learning meaningful and prepares students to use statistical techniques in the real world (Diamond \& Sztendur, 2002). Similarly, real-life data sets may be crucial for students who have not had industry experience (Bradstreet, 1996). Many authors (e.g., Garfield \& Ben-Zvi, 2009; Scheaffer, 2001; Singer \& Willett, 1990) argue strongly for the advantage of real-life data sets because this can be a meaningful and effective vehicle for teaching statistics, enabling students to develop analytical skills through realistic research situations. Moreover, real-life data not only assists teachers in communicating how data is analysed but also why it is analysed. The data should be motivating and of interest to students to show how statistical techniques can uncover meaningful information from numbers (Cobb, 1992; Garfield \& Ben-Zvi, 2009). Cobb (1992) states simply that "statistical concepts are best learned in the context of real data sets" (p. 7).

One way for teachers to obtain real-life data is for them to gather data from the students themselves (e.g., Neumann et al., 2010). Student-generated data also gives students experience in research design, data collection and analysis, as well as providing engaging, in-class interaction, and depth of learning in the process (Diamond \& Sztendur, 2002). Chottiner (1991) explained the use of real-life data consisting of personal, academic performance, time allocation, and miscellaneous data 
obtained from students completing the course. Chottiner (1991) suggested that the personal nature of the data increases interest in learning about statistical techniques that help gain meaning from the data. Although using data obtained directly from students is likely to create a strong interest, acquiring data in this way may not be appropriate for all circumstances and it requires the students and teachers invest adequate time to the exercise.

An alternative to creating data sets from students is to obtain data from published sources or data repositories. Online resources such as DASL (Data and Story Library), the Journal of Statistics Education (JSE) Data Archive, StatLib, and government statistics websites (e.g., Bureau of Statistics) are easy and quick alternatives for obtaining data. Also available are articles identifying sources of data sets (e.g., Willett \& Singer, 1992), online information hubs (e.g., Cologne University Statistical Resources) and books containing data (e.g., Andrews \& Herzberg, 1985; Chatterjee, Handcock, \& Simonoff 1995; Hamilton, 1990; Hand, Daly, Lunn, McConway, \& Ostrowski, 1994; Hodges, Krech, \& Crutchfield, 1975; Nelson, 1982; Tanner, 1990; Tufte, 1974). More specialised data sets can also be obtained. For example, Dierdorp et al. (2011) described how correlation and regression were taught within the context of dike monitoring using data generated by satellites that monitor deformation of the land surface.

In short, real-life data plays a central role in contemporary teaching approaches that aim to develop statistical knowledge and reasoning in students. However, there is little research on the effects that using real-life data has on student engagement and learning. Conducting research using an experimental approach to allow cause-effect inferences to be made is difficult in educational settings due to the ethical concern that a group of students would need to be taught statistics without using any real-life data. Nevertheless, Gordon (2004) emphasised that important information can be obtained through a qualitative analysis of reports given by statistics students about their learning. It was suggested that this approach increases attention on the students' actions and goals in the wider context of institutional and social factors. A qualitative approach was also adopted in the present study. In an introductory university statistics course, Neumann et al. (2010) did a qualitative evaluation of the use of data collected from students on student learning experiences. An examination of student feedback suggested that the use of the student data provided a means to structure in-class participation, was perceived by students to be a different approach, was reported by students to help maintain their interest, and was useful to them in developing their understanding of, and appreciation of the relevance of statistics.

The present study evaluated the use of real-life data during a first-year statistics course taught in a university psychology program. Unlike the study by Neumann et al. (2010) that evaluated the use of data collected from students, the present study focussed on the use of real-life data that were collected from published sources or data repositories on the World Wide Web. As noted by Earley (2007), an important consideration is that research should not focus only on the achievement outcomes associated with teaching strategies, but should also explore how they influence students' experiences. The research question addressed in this study was: what are students' perceptions on how the use of real-life data influences their experiences in learning statistics? The present investigation used a qualitative approach in which students were interviewed to elicit their reflections on how the use of real-life data was related to their engagement and learning. The interviews were transcribed and coded to determine the major themes captured in the responses. Based on prior recommendations suggesting the benefits of using real-life data, it was hypothesised that students would affirm that its use in teaching would be related to their learning experiences. Of particular interest, however, were the processes by which students perceived that the use of real-life data would be related to their learning and engagement.

\section{METHOD}

\subsection{DESCRIPTION OF THE COURSE AND THE USE OF REAL-LIFE DATA}

The statistics course was a first-year level compulsory course in the psychology program at Griffith University. The enrolment typically varies from 220 to 250 students. Topics covered in the course included an introduction to research methods, descriptive statistics, normal distribution and zscores, probability, sampling distributions, confidence intervals, and hypothesis testing using $t$ tests 
(one sample $t$-test, repeated measures $t$-test, independent groups $t$-test). The course was taught through weekly two-hour lectures and a one-hour tutorial class. The lectures followed the traditional lecturestyle format, although they included computer-based data analysis with SPSS software, simulations of statistics concepts, and video. The tutorials covered the practice of statistics through hand calculations and use of the SPSS software package.

Real-life data sets were integrated in the lectures and tutorial program. The data sets were obtained from various sources, including published articles, data repositories on the World Wide Web, and data collected from available sources by the course instructor. The data sets included those that had relevance to the discipline of psychology and those that were of general interest. The data sets were used to develop statistical concepts, rather than to merely provide a source of numbers for calculating statistics. The data sets and the statistical concepts they were used to develop were: Forbes list of the world's billionaires (descriptive statistics), eruption times of the Old Faithful geyser at Yellowstone National Park (descriptive statistics), salary of players from the Boston Celtics (descriptive statistics), men's swim times from the Sydney 2000 Olympics (identification of outliers), historical data on men and women marathon running times (correlation and prediction), the measurement of cocaine on Euro notes (sampling), mean and standard deviations of performance of leading sports people (z-scores), cost of providing care for people in mental health hospitals (one sample $t$-test), time taken to drink a beer (confidence intervals of the mean), and a data set that included brain size and IQ test scores of males and females (correlation and $t$-test for independent groups).

One or more of the real-life data sets formed the core of the lesson on a given statistical topic. For example, descriptive statistics were taught using the Forbes list of the world's billionaires. The students were introduced to the Forbes website and the method in which the data were collected from the website and entered into an SPSS data file. The format of the data in the SPSS data file was outlined (e.g., naming of variables, defining measurement scales). The graphical descriptive statistics of frequency charts, frequency distributions, pie charts, histograms, and stemplots were calculated based on the data. The resulting charts were discussed in terms of how they represented the data (e.g., how they were constructed) and allowed for the interpretation of the data (e.g., features of the distributions). Numerical descriptive statistics of mode, median, mean, quartiles, standard deviation, variance, range, interquartile range were similarly calculated based on the data set. The resulting values were discussed in terms of how they were calculated (e.g., statistical models/formula) and how they could be used to describe the population.

\subsection{DATA COLLECTION AND ANALYSES}

Participants The selection pool of participants consisted of students enrolled in the undergraduate introductory statistics course 1003PSY Research Methods and Statistics 1 at Griffith University. The teacher of this class (first author) played no part in the recruitment of students and was not told which students were contacted or who agreed to participate. Students were also informed of this process. As such, the selection and participation procedures provided student anonymity and allowed students to provide honest appraisals. To select participants, researchers initially grouped students by their course grade (high distinction, distinction, credit, pass, fail). The number of potential participants randomly selected from each grade group was proportional to the total number of students in the course that received each grade. Selected students were telephoned and invited to participate in the study. Of the 50 students who were randomly selected, five could not be contacted due to incorrect telephone number from the student records, five declined to participate (one each with a high distinction, distinction, and credit grade and two with a pass grade), and 40 agreed to participate.

Of the 40 students who originally consented to participate, one student who had received a fail grade could not be subsequently contacted and another student who had received a pass grade subsequently withdrew. The final sample thus consisted of 29 female and 9 male students with a mean age of 24.0 years $(S D=7.3)$. A number of these participants had completed previous post-secondary education, including a bachelor degree $(n=1)$, certificate $(n=3)$, and diploma $(n=4)$. The remaining participants had no previous post-secondary education. The final sample of participants reported attending most lectures throughout the course $(M=91.0 \%, S D=13.1 \%)$. All participants were offered a $\$ 7$ café voucher in appreciation of their participation in the study. 
Interview procedure The study was granted ethical approval by the institutional review board. The information sheet and consent form were mailed to participants after they had agreed to participate during the initial telephone contact by a research assistant. A second research assistant later contacted the participants to conduct the interview. This interviewer also had no involvement in the course. She had no involvement in the selection of participants and was blind to the grade that the student had obtained. Interviews were conducted after the course had been completed and the grades were known to the student.

At the beginning of the interview, all participants gave consent for the call to be recorded so that responses could be accurately transcribed during data coding. Each phone interview lasted approximately 20 minutes and started with semi-structured questions asking about the use of real-life data sets in course lecture materials, which included a reference to a particular example used during the course. Following this, participants were asked "What are your thoughts on the use of real-life data sets?" Where appropriate, students were asked to clarify or elaborate on responses. Further information was elicited by the interviewer using the prompts: "Did it help you engage with the material? How?", "Did it help motivate you to learn about statistics?", "What were some positive aspects to it?", and "What were some negative aspects to it?". Each question was asked of every participant. The interview also included questions about other teaching initiatives in the course and these have been reported elsewhere (Neumann, Hood, \& Neumann, 2009, 2012; Neumann, Neumann, \& Hood, 2010, 2011). At the completion of the interview, participants were asked about unrelated aspects of the course and several demographic based questions.

Data coding Responses from the recorded telephone interviews were entered directly into an electronic document. Each response was accompanied by a participant identification number. In total, there were 124 unique responses. Using a coding procedure described by Neuman (2006), open coding was first used to group the responses into preliminary analytical themes. This initial pass through the data set was done by a coder who had not been involved in the participant selection or interview process. The coder grouped the responses into themes of a similar conceptual nature. A category of responses that could not be grouped into a theme was also created. A second independent coder examined the responses and independently allocated them across the themes that had been created by the first coder. Because many responses included multiple themes, all of which could be placed into different categories, the two coders were given the freedom to code a whole response into a particular theme, or split responses into smaller components so that they could be coded into several themes. The two coders had $87 \%$ agreement in the coding decisions. The coding discrepancies generally centered on the degree to which responses should be split across different themes. For example, one coder had allocated the entire response "It helps you realise how important this subject was and how relevant it is to everything that you do" into a Real-Life Relevance category, whereas the other coder placed "It helps you realise how important this subject was" into the Understanding category, and "How relevant it is to everything that you do" into the Real-Life Relevance category. All discrepancies were resolved through discussion with a third individual.

Following the open coding process, there were seven themes. One of these themes was removed from further analyses because it contained statements from only $8 \%$ of participants. This theme was given the tentative label of Necessary and reflected statements in which students commented that using real-life data sets are essential to learn statistics. Responses that had been coded in the "Other" category were also disregarded. The final six themes were subjected to further examination. The label used to describe the theme was refined and a definition for each theme was developed such that it accurately reflected the nature of the responses within it. Example responses were also chosen for each theme. The labels, definitions, and examples created in this process were subjected to further discussion and refinement between the coders. Following the discussion, revisions were made to two category definitions and two category examples.

\section{RESULTS}

The themes that emerged from the interviews (see Table 1) included references to relevance, interest, learning, motivation, engagement with the material, and understanding. The theme cited most 
by students was labelled Real-Life Relevance (63\%). Students commented that the real-life data were related to a broader and more relevant perspective on statistics. For example, one student commented that using data "Gives real examples of how stats are used" and another noted that "It helps you realise how important this subject was and how relevant it is to everything that you do". The relevance associated with the real-life data may have emerged as a result of showing how the statistics could be applied in practical

Table 1. Themes, Definitions, and Percent that Gave a Response for Each Theme

\begin{tabular}{llc}
\hline \multicolumn{1}{c}{ Theme } & \multicolumn{1}{c}{ Definition } & Percent \\
\hline Real-Life Relevance & $\begin{array}{l}\text { Real-life data applies statistical concepts to practical situations to } \\
\text { give a broader and more relevant perspective of statistics }\end{array}$ & $63 \%$ \\
Interest & $\begin{array}{l}\text { Real-life data was related to interest and enjoyment when learning } \\
\text { about statistics }\end{array}$ & $58 \%$ \\
Learning and & $\begin{array}{l}\text { Real-life data played a role in learning and remembering of } \\
\text { statistical concepts and theory }\end{array}$ & $50 \%$ \\
Memory & $\begin{array}{l}\text { Real-life data gave encouragement and stimulation when learning } \\
\text { about statistics }\end{array}$ & $37 \%$ \\
Engagement & $\begin{array}{l}\text { Real-life data drew students in to learning about statistics and } \\
\text { make them involved and promoted further thought }\end{array}$ & $32 \%$ \\
Understanding & $\begin{array}{l}\text { Real-life data was related to gaining a clearer and more thorough } \\
\text { comprehension of statistics }\end{array}$ & $24 \%$ \\
\hline
\end{tabular}

situations combined with the fact that the situations were familiar or important to the students.

This was illustrated by comments such as "Because you can put it into perspective and actually apply what you know about" and "I think they were the best because it's good to have it drawn back to things otherwise stats seems like a theoretical math learning subject rather than what it is which is actual real-life application and everything and they were all things people could relate to".

Two themes that captured the ways in which real-life data sets were related to learning were labelled Learning and Memory (50\%) and Understanding (24\%). The Learning theme captured how learning and remembering statistical concepts and theory were related to the discussion of real-life data sets. Real-life data appeared to be particularly beneficial because of the abstract and mathematical nature of statistics as shown by the comments "It made it easier to remember because you remember the example with the stats formula" and "I think real examples stay in your mind". Some students suggested that using real data contexts played a role in assessments, as shown by the comment "It helped trigger memories and stuff when we were doing our tests". In some cases, the examples divided the material into more manageable pieces, for example "Helping with the learning of the materials and breaking it up", "It was something different and broke up the lecture material" and "It was nice to hear a story and not just stats but knowing there's more to it".

The theme Understanding (24\%) was allocated to a separate theme to Learning and Memory because the comments were diverse enough to require two categories. The theme Understanding was coded as relating more to comprehending and making sense of the material. In contrast, the theme Learning and Memory primarily captured the idea of merely being able to form memories or later retrieve the material. The use of real-life data was related to comments on the clarity of the material and how it played a role in working out and grasping statistical concepts. For example, one student noted "They were a good short tool to help you understand" and another student noted "They help you understand, you get a clear picture of it being explained and this helps you so I think it was good". 
The real-life data also promoted further thinking about the statistical concept in that it "made more sense....because you thought, you would understand it more".

Three themes emerged that related to more affective aspects than the previously discussed themes. A substantial number of students cited Interest (58\%). For example, it was commented that "It is more interesting than just providing theoretical sort of things" and "It probably made the work more fun and easier to concentrate because it was something different it wasn't quite as dry as the other content so it was good". Some of the real-life data were different or surprising and this may have played a role in its interest value, as shown by the comments "It was interesting rather than the plain old statistical sort of thing. It was more interesting because it was unusual" and "It was interesting to find out how they figured that out and got those statistics from that".

The theme of Motivation (37\%) also emerged for about one third of students illustrating that reallife data could stimulate some students to learn about statistics. For example, one student commented "They were a good motivational tool". Another student commented "It helped me have a reason for studying statistics". Material that is related to motivational aspects of learning statistics may be more likely to lead students to seek out and learn more about the concepts, as shown by the comments "It just motivated me to want to know more and get more information about it" and "It makes you want to learn about it a bit more".

The final theme was Engagement (32\%). This theme was distinguished from Interesting and Motivating in that it related to the potential role of real-life data sets in student involvement in the subject matter. One illustrative comment was "I think they helped you engage and experience statistics". The use of real-life data and its relationship with engagement may have helped to promote deep thinking, as shown by the comment "It just made you think about it a little bit more instead of just memorising things." Another student commented "You can engage because it's something that people know about" to suggest that using familiar variables and measures was an important factor of the engagement.

\section{DISCUSSION}

Analysis of student reports in the present study shows that the use of real-life data is associated with cognitive and affective/motivational themes in the students learning experiences. The most commonly cited theme was that regarding real-life relevance. This indicated that the use of real-life data sets was associated with gaining meaning from statistics in a more applied or practical sense. Half the sample gave comments that were coded as being related to learning and memory. These students generally believed that real-life data played a role in learning new concepts and techniques, as well as acting as a tool for remembering content. Almost one quarter of the sample reported that the use of real-life data was an important factor in understanding the course material more easily and completely. In addition, the students reported that real-life data was associated with their interest, motivation, and engagement in learning about statistics.

The themes that emerged in the present study are broadly consistent with the advice to use reallife data in teaching statistics. As noted by several authors (e.g., Bradstreet, 1996; Cobb, 1992; Garfield \& Ben-Zvi, 2008; Scheaffer, 2011), real-life data adds value to the learning process, as well as stimulating motivation through confrontation with real-life problems. Similarly, Diamond and Sztendur (2002) stated that real-life data is a motivating tool that allows deeper understanding of statistical methods, as well as providing enjoyment along the way. The finding of both cognitive (Aided Learning, Understanding) and affective/motivational (Interesting, Motivating, Engaging) themes in student responses in the present study are consistent with this conclusion. The theme of Real-life Relevance found in the present study is consistent with the notion that research experiences should be authentic and grounded in context (Cobb, 1992; Dierdorp et al., 2011; Garfield \& Ben-Zvi, 2009; Pfannkuch, 2011; Singer \& Willett, 1990). This theme is also consistent with approaches that aim to help students construct knowledge through their experiences with real-life data sets (Garfield \& Ben-Zvi, 2009) as based on the constructivist theory of learning. However, the present findings relate only to the end result of using real-life data. The methods used did not examine the learning processes in action during a lesson. To better understand the construction of knowledge using real-life data, it would be necessary to observe students before, during, and after lessons that incorporate reallife data sets. 
Based on the present results and the reports of others, a number of recommendations for teachers can be made on how best to select data sets for their classes. To enhance the benefits of real-life relevance in using the data, teachers should select data sets that concern topics in the students' field of study or are likely to be familiar to students in their daily life (e.g., see Gourgey, 2000; Hulsizer \& Woolf, 2009). In this way, the data is on a topic that is interesting or important to students to ensure that it engenders their engagement and motivation. For example, in the present application, data relating to the cost of providing care for people in mental health hospitals and the relationship between brain size and IQ were likely to appeal to the professional interests of psychology students. Data regarding the time taken to drink a beer in the present application may have been interesting only for the novelty factor or relevance to a limited number of university students. However, selecting reallife data merely for the potential effects in enhancing engagement and motivation should be avoided. It is also important that the statistics calculated from the data set will illustrate effectively the statistical concept being taught (Cobb \& McClain, 2004; Scheaffer, 2001).

While the use of real-life data may have some advantages for teachers and the learning outcomes of their students, there could also be potential disadvantages. Although there were no themes that emerged in the present study that showed strong disadvantages, isolated student comments suggested some caveats. For example, one student commented that the non-psychology based examples were not as good as the psychology examples. This suggests that teachers will need to spend the time to collect data sets that are relevant to the student's degree program (in this case, psychology). Despite the availability of data sets on the Internet, there may only be a limited number of data sets that could be relevant to the student and the statistical concept that the teacher wants to discuss. Another student commented about getting distracted during the lecture by other students that talked about the topic that the data was related to. Thus, while the data sets may have been advantageous for generating interest and engagement, the teacher should also be careful to keep real-life data from being distracting.

Although the present study did not show any themes related to ethical and copyright considerations, such issues may still be important when using real-life data sets in teaching (e.g., Morgan, 2001; Neumann et al., 2010). It is recommended that real-life data is used only when the data were collected in an ethical manner and when the participants have given their consent for the data to be available for use by other people. The present study did not find any student comments related to ethical issues. Teachers should also check for any copyright or intellectual property restrictions that could be associated with the data that they are using. Real-life data sets can also be "messy" in that they contain skewed distributions or outliers. While this can be turned into an advantage by teaching students about checking of distributions and how to deal with outliers, such discussion may take focus away from the main statistical concept that the teacher wants students to learn.

Limitations and future research The current study was based on a small number of students belonging to a specific cohort (i.e., students who had completed an introductory statistics course as part of a psychology degree). As such, the results may differ for students in other circumstances. For example, student characteristics such as year of study, degree type, and interest in statistics, as well as course characteristics such as the level of the statistics course being completed may influence the perceived benefits of real-life data. Further research examining how the present results generalise across different populations of students and different types of statistics courses is needed. It is expected that the dominant theme found in the present study, Real-Life Relevance, would be found across a variety of student populations and, in particular, among university students who are studying statistics in non-mathematical programs.

Bias can be introduced into a study through the methodology used. The anonymous participation of students and the use of an interviewer unrelated to the course and degree program of the students were designed to avoid participant and experimenter bias. The structure of the interview, however, may have promoted more positive responses than negative ones. This is because the first three direct questions were framed in a positive way. It was only the final question that asked about negative experiences. Future research should have the same number of positive and negative questions and counterbalance the order of the questions to control for potential bias introduced by the structure of the interview. In addition, additional questions could be asked to increase the diversity and depth of 
the responses from students. For instance, students can be asked "what if" or hypothetical questions or be asked to reflect upon teaching statistics from their teacher's perspective.

The themes of Motivation, Engagement, and Understanding were endorsed by only a minority of the sample. One interpretation of this finding is that students, on average, did not find the use of reallife data to be motivating, engaging, or important for understanding statistics. Alternatively, it may reflect upon the nature of the data collection method that was used. Students were interviewed and provided free-response answers to the questions. As such, the themes that emerged from an individual student are likely to be those that were most relevant to them and that came to mind during the interview. It is possible that some students may have found the use of real-life data to be motivating, but failed to mention this fact during their interview. To obtain more thorough information on the proportion of students that endorse each theme, it would be necessary to collect data in a way that allows students to make a rating or provide a comment in relation to all themes.

The observational approach used in the present study was therefore limited by being descriptive in nature. Such an approach is useful in the initial investigations of innovative teaching approaches to gain a better understanding of the nature of the impact the approach has on the experience of students. It also provides rich detail on which to base future research in this area and can lay the foundation for conducting quantitative studies. Future studies should take into consideration the six dimensions that emerged in the current study.

A further limitation of observational research is that it does not allow for cause-effect relationships to be drawn. For example, although many students stated that the use of real-life examples was engaging, it cannot be concluded that using the examples caused an increase in engagement. Such conclusion can be drawn only when the study has students placed in a treatment and a control group, selected by some random process. This may be particularly instructive in demonstrating cause-effect relationships of using real-life data on learning outcomes, such as academic achievement in the course. There are always practical constraints, however, on being able to assign students randomly to different teaching approaches.

The focus of the present study was on using real-life data sets, as opposed to data that is "contrived" or "made up" for the purpose of demonstrating a statistical concept. In this approach (see Lesser, 2011 for an example), mathematical calculations that underlie statistics are based purely on the numbers in the data set and not on how they originated. As such, students could gain many benefits if they practice the calculation and manipulation of numbers with any type of data set. It would be instructive for future research to examine what the particular benefits are of using real-life data when compared to data that has not been collected from real observations. Based on the present research, it would be expected that actual data would be better able to demonstrate the real-life relevance of statistics. Real-life data would also be expected to engender more interest, motivation, and engagement in students than data sets that are not based on real observations.

Conclusion In conclusion, the present research has shown that several themes seem to emerge when real-life data are involved in the teaching of statistics. When real-life data is used to illustrate statistical concepts, practice calculations, and show the application of statistics, there is some association with specific types of student learning experiences such as relevance, understanding and learning, interest, motivation, and engagement. The present findings suggest that, in line with the recommendations of other authors (Bradstreet, 1996; Cobb, 1992; Garfield \& Ben-Zvi, 2008; Moore, 1997; Scheaffer, 2001) it might be fruitful for statistics teachers to incorporate real-life data into their teaching.

\section{ACKNOWLEDGEMENTS}

The assistance of Tiffany Middleton and Sandor Heng in participant recruitment and data scoring is acknowledged. Thanks also to Mitchell Shepherd for assistance with manuscript preparation. This project received partial support from the Griffith Teaching in Psychology Research Group. 


\section{REFERENCES}

American Statistical Association (2005). Guidelines for assessment and instruction in statistics education: College report. Alexandria, VA: Author.

Andrews, D. F., \& Herzberg, A. M. (1985). Data: A collection of problems from many fields for the student and research worker. New York: Springer-Verlag.

Australian Bureau of Statistics. Retrieved August 14, 2012 from http://www.abs.gov.au/

Bradstreet, T. E. (1996). Teaching introductory statistics courses so that nonstatisticians experience statistical reasoning. The American Statistician, 50(1), 69-78.

Budé, L., Van De Wiel, M. W. J., Imbos, T., Candel, M. J. J. M., Broers, N. J., \& Berger, M. P. F. (2007). Students' achievements in a statistics course in relation to motivational aspects and study behavior. Statistics Education Research Journal, 6(1), 5-21.

[Online: http://iase-web.org/documents/SERJ/SERJ6(1)_Bude.pdf ]

Chatterjee, S., Handcock, M. S., \& Simonoff, J. S. (1995). A casebook for a first course in statistics and data analysis. New York: John Wiley.

Chottiner, S. (1991). Using real (intimate) data to teach applied statistics. The American Statistician, 45(2), 169.

Cobb, G. (1992). Teaching statistics. In L. A. Steen (Ed.), Heeding the call for change: Suggestions for curricular action (pp. 3-33). Washington, DC: Mathematical Association of America.

Cobb, P., \& McClain, K. (2004). Principles of instructional design for supporting the development of students' statistical reasoning. In D. Ben-Zvi \& J. Garfield (Eds.), The challenge of developing statistical literacy, reasoning, and thinking (pp. 375-396). Dordrecht, The Netherlands: Kluwer Academic Publishers.

Cologne University Statistical Resources. Retrieved August 14, 2012, from http://www.uni-koeln.de/themen/statistik/data/index.e.html

Connor, D., \& Davies, N. (2002). An international resource for learning and teaching. Teaching Statistics, 24(2), 59-61.

Dierdorp, A., Bakker, A., Eijkelhof, H., \& van Maanen, J. (2011). Authentic practices as contexts for learning to draw inferences beyond correlated data. Mathematical Thinking and Learning, 13(1), $132-151$.

Diamond, N. T., \& Sztendur, E. M. (2002). Simplifying consulting problems for use in introductory statistics lectures. In B. Phillips (Ed.), Proceedings of the sixth International Conference on Teaching Statistics, Cape Town, South Africa. Voorburg, The Netherlands: International Statistical Institute.

[Online: http://iase-web.org/documents/papers/icots6/5e4_diam.pdf ]

Dunn, D. S., Smith, R. A., \& Beins, B. C. (Eds.). (2007). Best practices for teaching statistics and research methods in the behavioral sciences. Mahwah, NJ: Lawrence Erlbaum Associates.

Earley, M. A. (2007). Students' expectations of introductory statistics instructors. Statistics Education Research Journal, 6(1), 51-66. [Online: http://iase-web.org/documents/SERJ/SERJ6(1)_Earley.pdf]

Franklin, C. A., \& Garfield, J. (2006). The guidelines for assessment and instruction in statistics education (GAISE) project: Developing statistics education guidelines for pre K-12 and college courses. In G. F. Burrill (Ed.), Thinking and reasoning about data and chance: Sixty-eighth NCTM yearbook (pp. 345-375). Reston, VA: National Council of Teachers of Mathematics.

Garfield, J., \& Ben-Zvi, D. (2008). Developing students' statistical reasoning: Connecting research and teaching practice. Dordrecht, The Netherlands: Springer.

Garfield, J., \& Ben-Zvi, D. (2009). Helping students develop statistical reasoning: Implementing a statistical reasoning learning environment. Teaching Statistics, 31(3), 72-77.

González, G. M., \& Birch, M. A. (2000). Evaluating the instructional efficacy of computer-mediated interactive multimedia: Comparing three elementary statistics tutorial modules. Journal of Educational Computing Research, 22(4), 411-436.

Gordon, S. (2004). Understanding students' experiences of statistics in a service course. Statistics Education Research Journal, 3(1), 40-59.

[ Online: http://iase-web.org/documents/SERJ/SERJ3(1)_gordon.pdf ] 
Gourgey, A. F. (2000). A classroom simulation based on political polling to help students understand sampling distributions. Journal of Statistics Education, 8(3). [ Online: http://www.amstat.org/PUBLICATIONS/JSE/secure/v8n3/gourgey.cfm ]

Hamilton, L. C. (1990). Modern data analysis: A first course in applied statistics. Pacific Grove, CA: Brooks-Cole.

Hand, D. J., Daly, F., Lunn, A. D., McConway, K. J., \& Ostrowski, E. (1994). A handbook of small data sets. London: Chapman \& Hall.

Hodges, J. L., Krech, D., \& Crutchfield, R. S. (1975). Statlab: An empirical introduction to statistics. New York: McGraw-Hill.

Hogg, R. V. (1991). Statistical education: Improvements are badly needed. The American Statistician, 45(4), 342-343.

Holmes, P. (2002). Some lessons to be learned from curriculum developments in statistics. In B. Phillips (Ed.), Proceedings of the Sixth International Conference on Teaching Statistics, Cape Town, South Africa. Voorburg, The Netherlands: International Statistical Institute. [Online: http://iase-web.org/documents/papers/icots6/2d6 holm.pdf ]

Hulsizer, M. R., \& Woolf, L. M. (2009). A guide to teaching statistics: Innovations and best practices. Malden, MA: John Wiley \& Sons.

Lesser, L. M. (2011). Simple data sets for distinct basic summary statistics. Teaching Statistics, 33(1), 9-11.

Makar, K., \& Ben-Zvi, D. (2011). The role of context in developing reasoning about informal statistical inference. Mathematical Thinking and Learning, 13(1\&2), 1-4.

Moore, D. S. (1997). New pedagogy and new content: The case of statistics. International Statistical Review, 65(2), 123-137.

Morgan, B. L. (2001). Statistically lively uses for obituaries. Teaching of Psychology, 28(1), 56-58.

Morris, E. J., Joiner, R., \& Scanlon, E. (2002). The contribution of computer-based activities to understanding statistics. Journal of Computer Assisted Learning, 18(2), 116-126.

Nelson, W. (1982). Applied life data analysis. New York: John Wiley.

Neuman, W. L. (2006). Social research methods: Qualitative and quantitative approaches. New York: Pearson Education Inc.

Neumann, D. L., Hood, M., \& Neumann, M. M. (2009). Statistics? You must be joking: The application and evaluation of humor when teaching statistics, Journal of Statistics Education, 17(2). [Online: http://www.amstat.org/publications/jse/v17n2/neumann.pdf]

Neumann, D. L., Hood, M., \& Neumann, M. M. (2012). An evaluation of computer-based interactive simulations in the assessment of statistical concepts. International Journal for Technology in Mathematics Education, 19(1), 17-23.

Neumann, D. L., Neumann, M. M., \& Hood, M. (2010). The development and evaluation of a survey that makes use of student data to teach statistics. Journal of Statistics Education, 18(1). [Online: http://www.amstat.org/publications/jse/v18n1/neumann.pdf ]

Neumann, D. L., Neumann, M. M. \& Hood, M. (2011). Evaluating computer-based simulations, multimedia and animations that help integrate blended learning with lectures in first year statistics. Australasian Journal of Educational Technology, 27(2), 274-289.

Onwuegbuzie, A. J., \& Wilson, V. A. (2003). Statistics anxiety: Nature, etiology, antecedents, effects, and treatments - a comprehensive review of the literature. Teaching in Higher Education, 8(2), 195-209.

Pfannkuch, M. (2011). The role of context in developing informal statistical inferential reasoning: A classroom study. Mathematical Thinking and Learning, 13(1\&2), 27-46.

Rumsey, D. J. (2002). Statistical literacy as a goal for introductory statistics courses. Journal of Statistics Education, 10(3).

[Online: http://www.amstat.org/publications/jse/v10n3/rumsey2.html ]

Scheaffer, R. L. (2001). Statistics education: Perusing the past, embracing the present, and charting the future. Newsletter for the Section on Statistical Education, 7. [Online: http://www.amstat.org/sections/educ/newsletter/v7n1/Perusing.html]

Singer, J. D., \& Willett, J. B. (1990). Improving the teaching of applied statistics: Putting the data back into data analysis. The American Statistician, 44(3), 223-230.

Tanner, M. A. (1990). Investigations for a course in statistics. New York: Macmillan. 
Tremblay, P. F., Gardner, R. C., \& Heipel, G. (2000). A model of the relationships among measures of affect, aptitude, and performance in introductory statistics. Canadian Journal of Behavioural Science, 32(1), 40-48.

Tufte, E. R. (1974). Data analysis for politics and policy. Englewood Cliffs, NJ: Prentice-Hall.

Willett, J. B., \& Singer, J. D. (1992). Providing a statistical "model": Teaching applied statistics using real-world data. In F. Gordon \& S. Gordon (Eds.), Statistics for the twenty-first century (pp. 8398). Washington, DC: Mathematical Association of America.

DAVID NEUMANN

School of Applied Psychology, Gold Coast Campus

Griffith University

QLD, Australia, 4222 